\title{
APLICAÇÃO DE GEOTECNOLOGIAS PARA ANÁLISE E MAPEAMENTO DE PROCESSOS EROSIVOS NA MICROBACIA DO ARROIO SARANDI, SANTA MARIA, RS
}

\author{
Naijara Klafke Dalla Lana $^{(\mathrm{a})}$, Rodrigo Corrêa Pontes ${ }^{(\mathrm{b})}$, Iago Turba Costa ${ }^{(\mathrm{c})}$, Valmir Vieira ${ }^{(\mathrm{d})}$ \\ (a) Mestranda em Geografia, Departamento de Geociências/ Universidade Federal de Santa Maria, Email: \\ naijaraklafke@hotmail.com \\ (b) Colégio Politécnico da Universidade Federal de Santa Maria, Email: rodrigocorreapontes@gmail.com \\ (c) Geógrafo, Universidade Federal de Santa Maria, Email: iagoturba@ hotmail.com \\ (d) Colégio Politécnico da Universidade Federal de Santa Maria, Email: valviera @ yahoo.com.br
}

\section{Eixo: GEOTECNOLOGIAS E MODELAGEM ESPACIAL EM GEOGRAFIA FÍSICA}

\begin{abstract}
RESUMO
Fatores antrópicos e naturais são os principais condicionantes para o processo de formação de erosão. Tais variáveis demonstram a necessidade de conhecer o meio físico em que se formam esses processos, a fim de evitá-los ou conter os danos que podem causar. Para isso, deve-se entender o funcionamento de condicionantes como a declividade, o uso e a cobertura do solo, o relevo e o tipo de solo. O presente trabalho tem como objetivo um estudo preliminar acerca de uma vertente sofrendo processos erosivos, no distrito de São Valentim, pertencente à Santa Maria. Procedeu-se, também, à caracterização e delimitação automática da bacia hidrográfica em que está inserida a área de estudo, bem como à produção dos mapas de declividade, hipsometria, uso do solo e geológico. Além de contribuir para um melhor conhecimento da área em questão, esta produção poderá ser utilizada como auxílio em estudos futuros sobre erosão.
\end{abstract}

Palavras chave: Geotecnologias, mapeamento, processos erosivos.

\section{Introdução}

Geoprocessamento segundo Câmara, Davis e Monteiro (2001), pode ser definido como a disciplina do conhecimento que utiliza técnicas matemáticas e computacionais para o tratamento da informação geográfica e que vem influenciando de maneira crescente as áreas de Cartografia, Análise de Recursos Naturais, dentre outras. Os Sistemas de Informações Geográficas (SIGs) possibilitam a análise integrada de diferentes dados e a produção de materiais diversos. Os SIGs são sistemas em computador que fornecem informações não só sobre os fenômenos, mas também sobre a localização espacial. Para Câmara, Medeiros e Monteiro (2002), um SIG é uma ferramenta computacional a serviço do Geoprocessamento, que permite realizar análises complexas, ao integrar dados de diversas fontes e ao criar um banco de dados georreferenciados, bem como automatizar a produção de documentos cartográficos. Do ponto de vista da aplicação, utilizar um SIG implica escolher as representações computacionais mais adequadas para capturar a semântica de seu domínio de aplicação. Já do ponto de vista da tecnologia, de acordo com Câmara, Medeiros e Monteiro (2002), desenvolver um SIG significa oferecer o conjunto mais amplo possível de estruturas de dados e algoritmos capazes de representar a grande diversidade de concepções do espaço. 


\section{Objetivos}

A ação tem como objetivo geral a coleta de pontos a campo e a confecção de mapas temáticos da da voçoroca Buraco Grande, pertencente à bacia do Arroio Sarandi no distrito de São Valentim, Santa Maria. Como objetivos específicos, foram propostos:

a) Coletar pontos no perímetro da voçoroca e da microbacia do Arroio Sarandi a fim de reunir dados para elaboração posterior de mapas temáticos;

b) Representar cartograficamente a voçoroca e a microbacia do Arroio Sarandi em estudo, através de mapas temáticos de localização, de declividade, limite da bacia, geológico, hipsométrico e uso da terra.

\section{Fundamentação teórica}

Um SIG pode ser utilizado, pelo menos, para três finalidades: produção de mapas, análise espacial de fenômenos e banco de dados geográficos, com funções de armazenamento e consulta de informação espacial. Conforme Branco (1997) diversas funções desenvolvidas pelos SIG’s sempre pertenceram ao trabalho de pesquisa da Geografia, porém estes sistemas possibilitam uma forma mais eficiente de atingir os resultados, sendo que muitas são impossíveis de ser elaboradas manualmente. Em geral, um Sistema de Informações Geográficas, depende de três componentes básicos para ser implementado como banco de dados, hardware e software.

Conforme Ávila (2009) a microbacia do Arroio Sarandi, apresenta inúmeros focos de erosão como sulcos, ravinas feições de pseudo-carste e voçorocas. Para o estudo da voçoroca é necessário abordarmos alguns conceitos. De acordo com Guerra (1976) bacia hidrográfica é o "conjunto de terras drenadas por um rio principal e seus afluentes".

Conforme Silva (2003) os processos erosivos fazem parte da evolução natural do meio físico e da alteração do relevo. O processo denominado intemperismo rompe as rochas formando partículas menores, estas podendo ser transportadas facilmente, promovendo um processo conhecido como erosão. Conforme Guerra (1975) erosão é a "destruição das saliências ou reentrâncias do relevo, tendendo a um nivelamento ou colmatagem". De modo geral conforme Boardmann (1990) são distintas duas formas de abordar os processos erosivos. A erosão natural (geológica) e erosão acelerada (antrópica), sendo que a intensidade é superior a da formação do solo, impedindo sua recuperação natural. De todos agentes transportadores, a água é o elemento mais erosivo e corrosivo. Todas suas formas possuem um grande potencial erosivo.

De acordo com Bertoni e Lombardi Neto (1999), a erosão natural desenvolve-se de forma lenta e paulatina, sendo considerada de ocorrência normal e benéfica, pois se resultara inúmeras formas de relevo da superfície terrestre como colinas, planícies extensas e vales férteis. A erosão acelerada, 
OS DESAFIOS DA GEOGRAFIA FÍSICA NA FRONTEIRA DO CONHECIMENTO

Instituto de Geociências - Unicamp

Campinas - SP

28 de Junho à 02 de Julho de 2017

conforme Bigarella (2003) se desenvolve quando o equilíbrio é afetado, numa breve escala de tempo, não podendo atingir uma nova compensação de forças.

Gotas de chuva, em ambientes secos, criam erosão através do impacto e do respingo das gotículas de água, movendo as partículas de solo. Para Guerra e Mendonça (2004), o impacto da gota de água da chuva resulta na compactação do solo pela formação de crostas (crusts) que irão dificultar e impedir a infiltração da água da chuva. A água quando escoa sobre a superfície do solo carrega junto partículas, enquanto se move em direção a outros cursos de água (arroios, córregos e riachos), gerando desta forma a erosão superficial.

Cabe salientar que os processos erosivos em grandes dimensões são responsáveis por severas perdas econômicas e ambientais de uma determinada área, aonde estes venham a se desenvolver. O escoamento nas encostas dos solos atua como um agente de transporte, removendo as partículas soltas do solo. No entanto, principalmente atua como um agente de erosão removendo partículas do solo quando flui sobre a superfície quando não há vegetação. Conforme Bertoni e Lombardi Neto (1985) solos arenosos são mais suscetíveis ao processo erosivo, permitindo rápida infiltração das águas e retardando o escoamento superficial. Os solos com uma pequena quantidade de partículas tamanho argila, possuem baixa coesão, tendo uma menor resistência à erosão, sendo esta verificada mesmo em pequenas enxurradas.

Conforme Bastos (1999), a terminologia voçoroca é oriunda do termo Tupi-Guarani, "mboso'roka", que significa rompimento, sendo definida como uma ravina de

grandes dimensões gerada pela grande concentração do fluxo superficial, promovida pela ação antrópica, combinada com a ação do fluxo subsuperficial e subterrâneo. De acordo com o Instituto de Pesquisas Tecnológicas (1991) as erosões por voçoroca constituem-se no estágio mais avançado da erosão, sendo caracterizadas pelo avanço em profundidade das ravinas até estas atingirem o lençol freático ou o nível de água do terreno. As zonas erodidas e em expansão nos são responsáveis pelo arrastamento da cobertura vegetal e abertura de grandes ravinas e voçorocas, dificultando, quando não impedindo, o estabelecimento de vegetação nestas localidades, exceto no caso das comunidades instaladas no interior das ravinas.

Segundo Bastos (1999) os mecanismos envolvidos nestes processos são complexos e apresentam uma interrelação de fatores climáticos, pedogênicos, topográficos, vegetacionais que interveem no fenômeno.

\section{Metodologia}

A microbacia do Arroio Sarandi, onde se encontra a voçoroca, localiza-se no município de Santa Maria e no município de Dilermando de Aguiar (Figura 1), na região central do Rio Grande do Sul, entre as

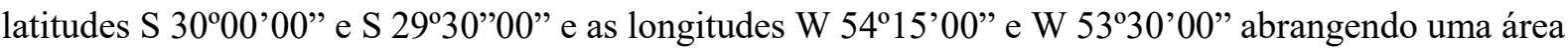
de $334,80 \mathrm{~km}^{2}$. A referida microbacia classifica-se como endorréica, cujos canais são de primeira, 
XVII Simpósio Brasileiro

de Geografia Fisica Aplicada

I Congresso Nacional

de Geografia Física

\section{OS DESAFIOS DA GEOGRAFIA FÍSICA NA FRONTEIRA DO CONHECIMENTO \\ Instituto de Geociências - Unicamp \\ Campinas - SP \\ 28 de Junho à 02 de Julho de 2017}

segunda e terceira ordens. Os canais fluviais apresentam convergências em ângulos retos que constituem diferentes formas atribuídas aos fenômenos tectônicos (ÁVILA, 2009, p. 52).

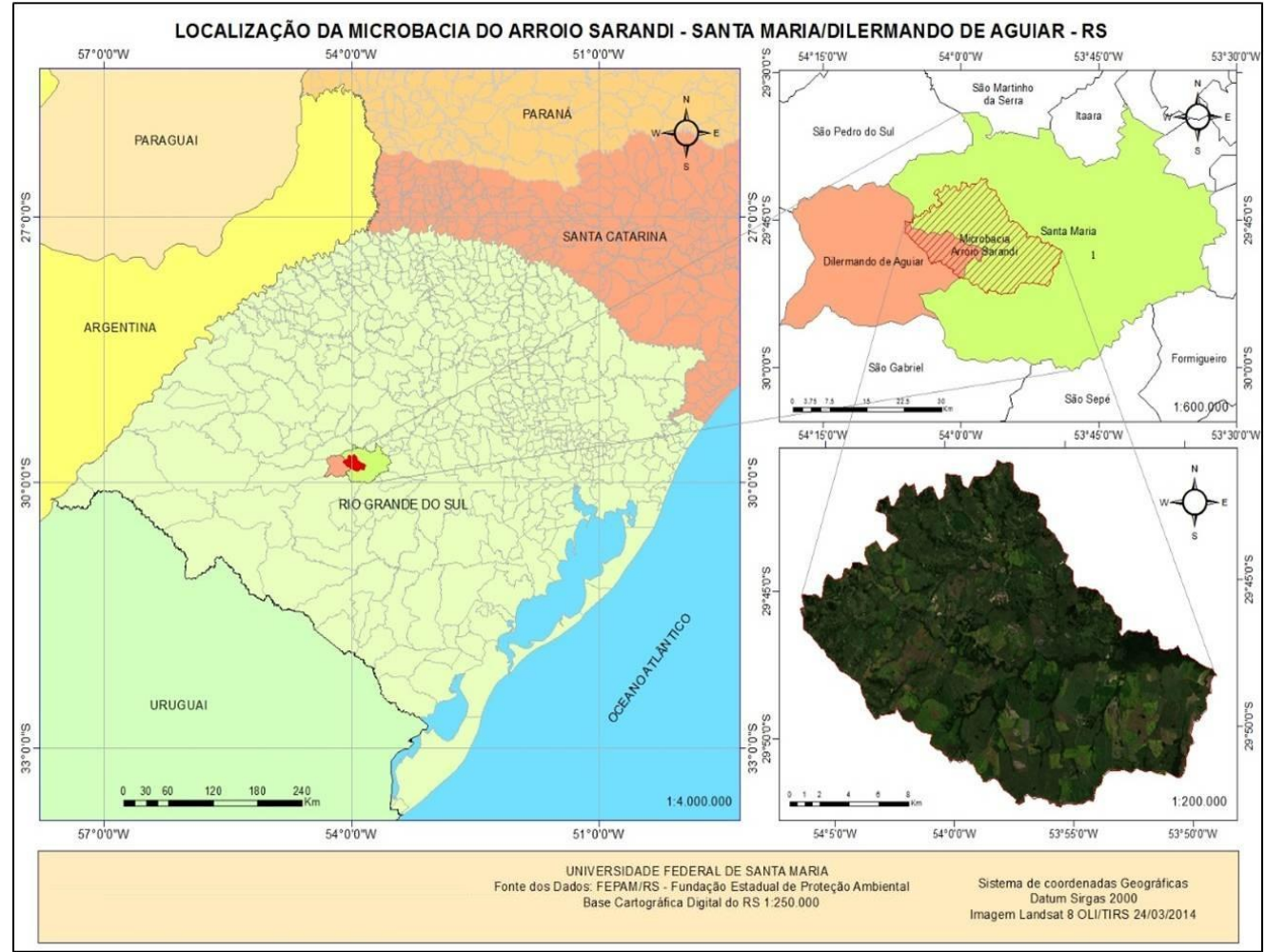

Figura 1- Mapa de localização da área de estudo da microbacia do Arroio Sarandi. Fonte: Autor

O relevo do entorno da voçoroca do Buraco Fundo, como é denominada a voçoroca de São Valentim, é formado por colinas levemente onduladas. As particularidades das formações geológicas da microbacia do Arroio Sarandi seguem as observações e os estudos elaborados pela Companhia de Pesquisa de Recursos Minerais (2010). A Formação Sanga do Cabral, uma das formações que constituem essa microbacia, apresenta-se em corpos tabulares ou lenticulares alongados, brechas e conglomerado intraformacional, com siltito e raro argilito. Há, ainda, depósito de ambiente continental, fluvial entrelaçado, contendo fragmentos de vertebrados fósseis (anfíbios e répteis), depositado no Triássico Inferior. A Formação Santa Maria divide-se em dois membros: Passo das Tropas e Alemoa. O primeiro varia entre arenito e arenito conglomerático. O segundo constitui-se em um siltito argiloso maciço, contendo fósseis de tetrápodes. Ambos os membros são originários de depósitos de canais fluviais de moderada sinuosidade e de planícies de inundação e lacustres em ambiente continental, depositados durante o Triássico Médio. Por fim, também há depósitos aluviais com areia grossa a fina, cascalho e sedimento síltico-argiloso em calhas de rio e planícies de inundação, depositados durante o Holoceno.

Os materiais utilizados na elaboração dos mapas e do levantamento topográfico: um par de receptores GNSS RTK L1/L2 GPS \& GLONASS marca TOPCON, modelo HYPER LITE+, tripé de alumínio, bastão graduado de 8 metros, bastão graduado de 2,5 metros, controladora FC 250 TOPCON, piquetes 
OS DESAFIOS DA GEOGRAFIA FÍSICA NA FRONTEIRA DO CONHECIMENTO

Instituto de Geociências - Unicamp

Campinas - SP

28 de Junho à 02 de Julho de 2017

de madeira e tinta spray, trena de aço com $7 \mathrm{~m}$. Os materiais utilizados para os mapas temáticos foram: imagens SRTM formato GEOTIFF (16 bits), resolução espacial 90 metros compatível com a escala 1:250.000 (IBGE), SH-22-V-C e SH-22-X-D , arquivos digitais para SIG - base cartográfica digital do RS escala 1:250.000 da FEPAM-RS, mapa geológico do RS da CPRM escala 1:750.000, imagem Landsat 8 OLI/TIRS composição RGB 432, resolução espacial de 30 metros, órbita/ponto 223/81 do dia $24 / 03 / 2014$

Programa ArcGIS versão 10.1 licença usuário 369462, sistema de Automação topográfica, POSIÇÃO licença usuário 3030-4 e Google Earth versão 7.1.2 gratuita

A delimitação da microbacia do Arroio Sarandi, onde se insere a área de estudo, foi elaborada por procedimentos de extração automática das drenagens do programa ArcGIS 10.1, com as ferramentas do Spatial Analyst para hidrologia conforme as etapas descritas a seguir: a) definição da direção de fluxo da drenagem em cada célula (Flow Direction) que gera uma grade regular com as direções baseadas na maior linha de declividade encontrada no modelo de elevação do terreno. A direção de fluxo deve conter apenas os valores 1, 2, 4, 8,16, 32, 64 e 128, que representam as oito células adjacentes por onde a água deve fluir; b) identificação e preenchimento dos vazios na imagem; e c) acumulação do fluxo (Flow Accumulation) de acordo com Rennó et al. (2008). A direção de fluxo define as relações hidrológicas entre pontos diferentes dentro de uma bacia hidrográfica. Segundo Sobrinho et al. (2010), a continuidade topológica para as direções de fluxo é necessária para que uma drenagem funcional possa existir. As conexões hidrológicas de direção de fluxo entre dois pontos em uma superfície não são as mesmas que aquelas baseadas em distância euclidiana.

\section{Resultados e discussões}

A seguir, são apresentados os resultados preliminares da análise feita na microbacia do Arroio Sarandi, bem como as pretensões futuras para a continuidade deste estudo. Como resultados, foram elaborados mapas temáticos demonstrando a situação presente na área de estudo. Sobre o mapa de declividade (Figura 2), área de estudo apresenta valores de declividade mais evidentes nas classes de 0 a $3 \%$ e de 3 a $6 \%$. O primeiro intervalo representa $28,29 \%$ do total e corresponde ao que é classificado como plano. Já o segundo intervalo corresponde a 29,23\% do total, sendo classificado como suave ondulado e com pouca movimentação topográfica. Nas áreas em que o terreno é classificado como moderadamente ondulado (6 a 12\% de declividade), os valores correspondem a 13,98\% do total. Outros 4,61\% são classificados como ondulado, apresentando entre 12 e $20 \%$ de declividade. Pode-se afirmar, assim, que o local de estudo apresenta baixa representatividade em áreas com declividade entre 20 e 45\% (apresentando 0,002\%) e acima de $45 \%$ de declividade. 


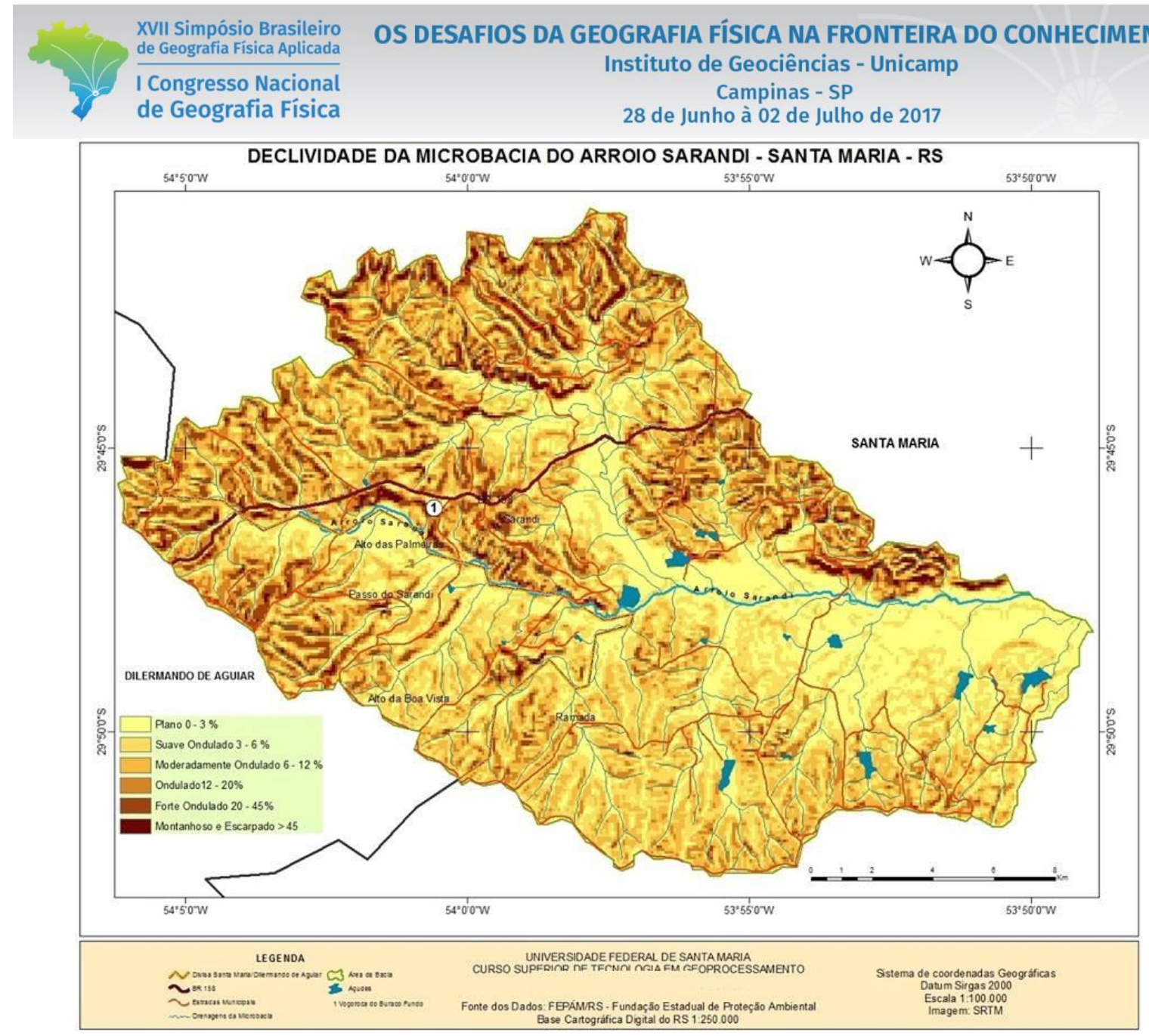

Figura 2 - Mapa de declividade da microbacia do Arroio Sarandi. Fonte: Autor.

De acordo com o mapa hipsométrico (Figura 3), embora as altitudes da bacia variem de 60 a 220 metros de altitude, a maior parte está entre 60 e 125 metros (60-80 m correspondente a 24,8\%, 80-100 m correspondente a $29,44 \%$ e $100-125$ m correspondente a 23,35\%). . As altitudes entre 125 e 150 metros correspondem a 15,74\%, com 57,30 Km² de área. Já as áreas entre 150 e 200 metros representam apenas $7,18 \%$ do total analisado. 


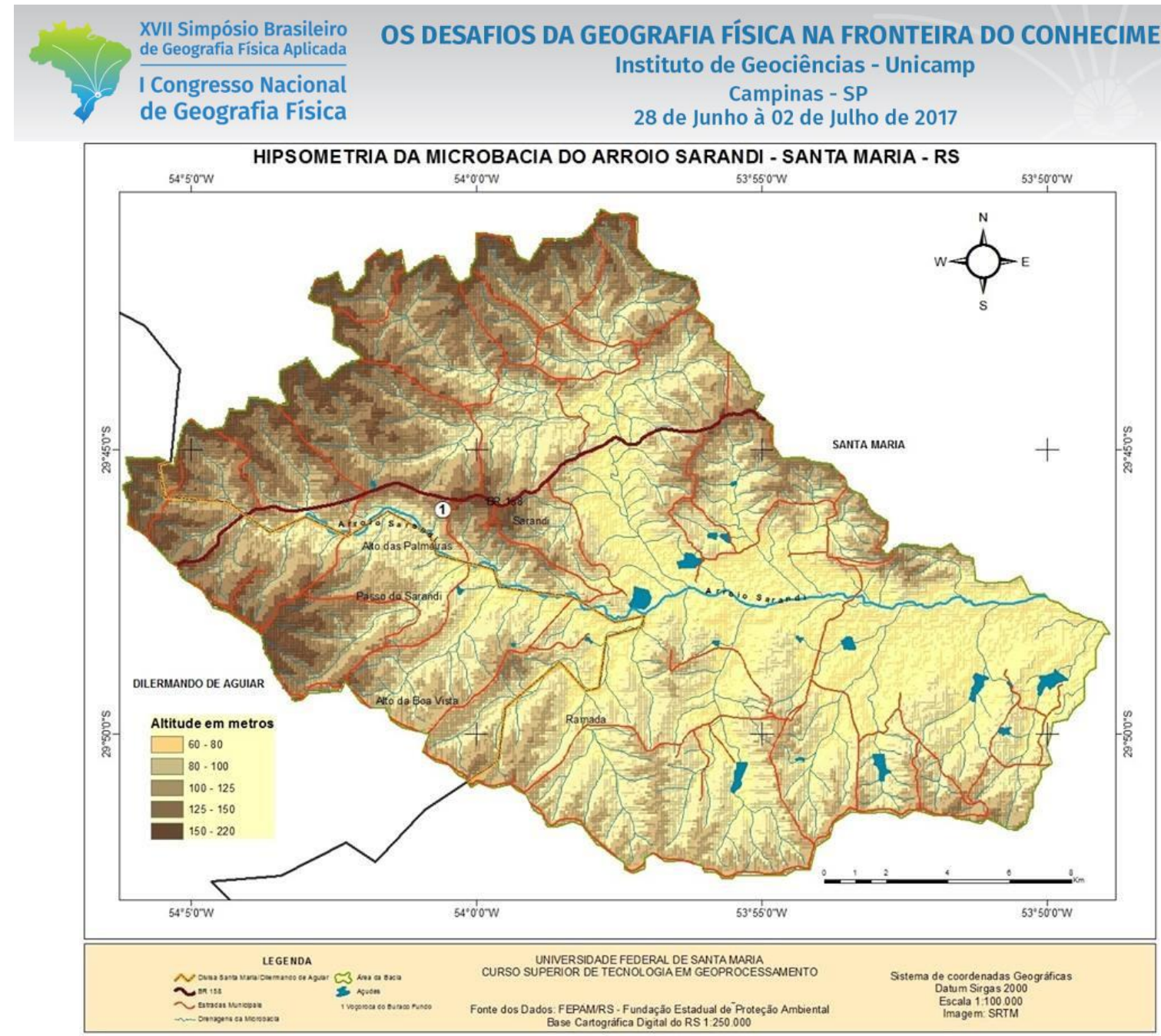

Figura 3 - Mapa hipsométrico da microbacia do Arroio Sarandi. Fonte: Autor.

No mapa de uso do solo (Figura 4) pode-se observar o uso do solo e sua representatividade por meio das classes atribuídas. As áreas de agricultura têm maior representatividade na área de estudo, com 43,97\% do total $\left(147,21 \mathrm{Km}^{2}\right)$, seguido dos campos e das pastagens, que ocupam $25,42 \%$ do total da área $(85,10$ $\mathrm{Km}^{2}$ ), Florestas e matas ciliares, por sua vez, ocupam cerca de $58,43 \mathrm{Km}^{2}$ de área, isto é, $17,45 \%$ do total. Já as áreas de solo exposto têm representatividade de $12,18 \%\left(40,79 \mathrm{Km}^{2}\right)$, enquanto que a água representa $0,98 \%$ do total da área $\left(3,27 \mathrm{Km}^{2}\right)$. 


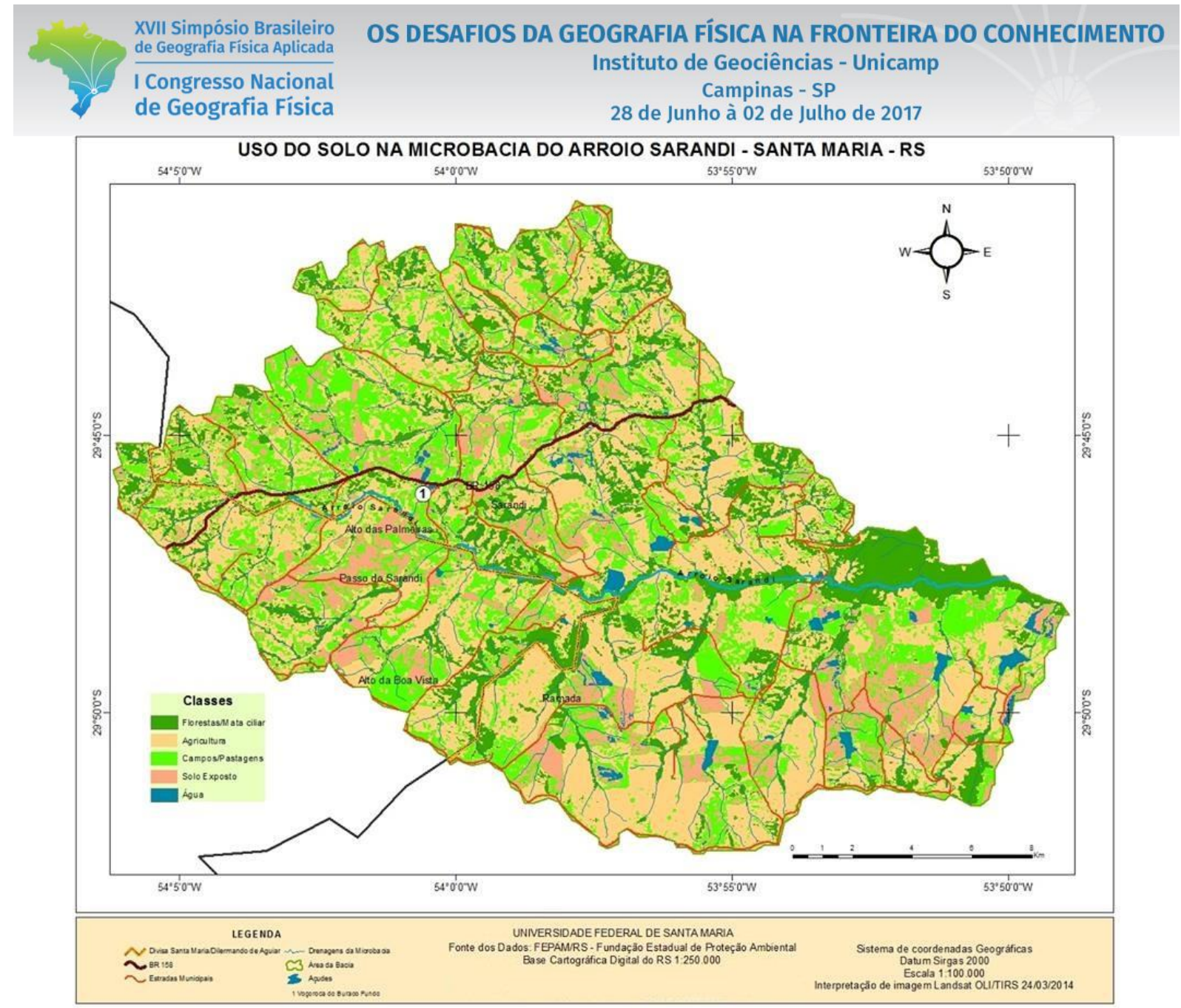

Figura 4 - Mapa do uso do solo da microbacia do Arroio Sarandi. Fonte: Autor.

Conforme a o mapa geológico (Figura 5), a formação predominante na área de estudo é a Sanga do Cabral, que corresponde a $185,23 \mathrm{Km}^{2}(55,32 \%)$, em corpos tabulares ou lenticulares alongados, brecha e conglomerado intraformacional, siltito e raro argilito. Já a formação Santa Maria, com arenito e arenito conglomerático e com pelitos subordinados, e siltito argiloso maciço, ocupa 27,66\% da área total, com $92,62 \mathrm{Km}^{2}$ e com os sedimentos aluvionares ocupando $17,01 \%$ de área $\left(56,95 \mathrm{Km}^{2}\right)$. 

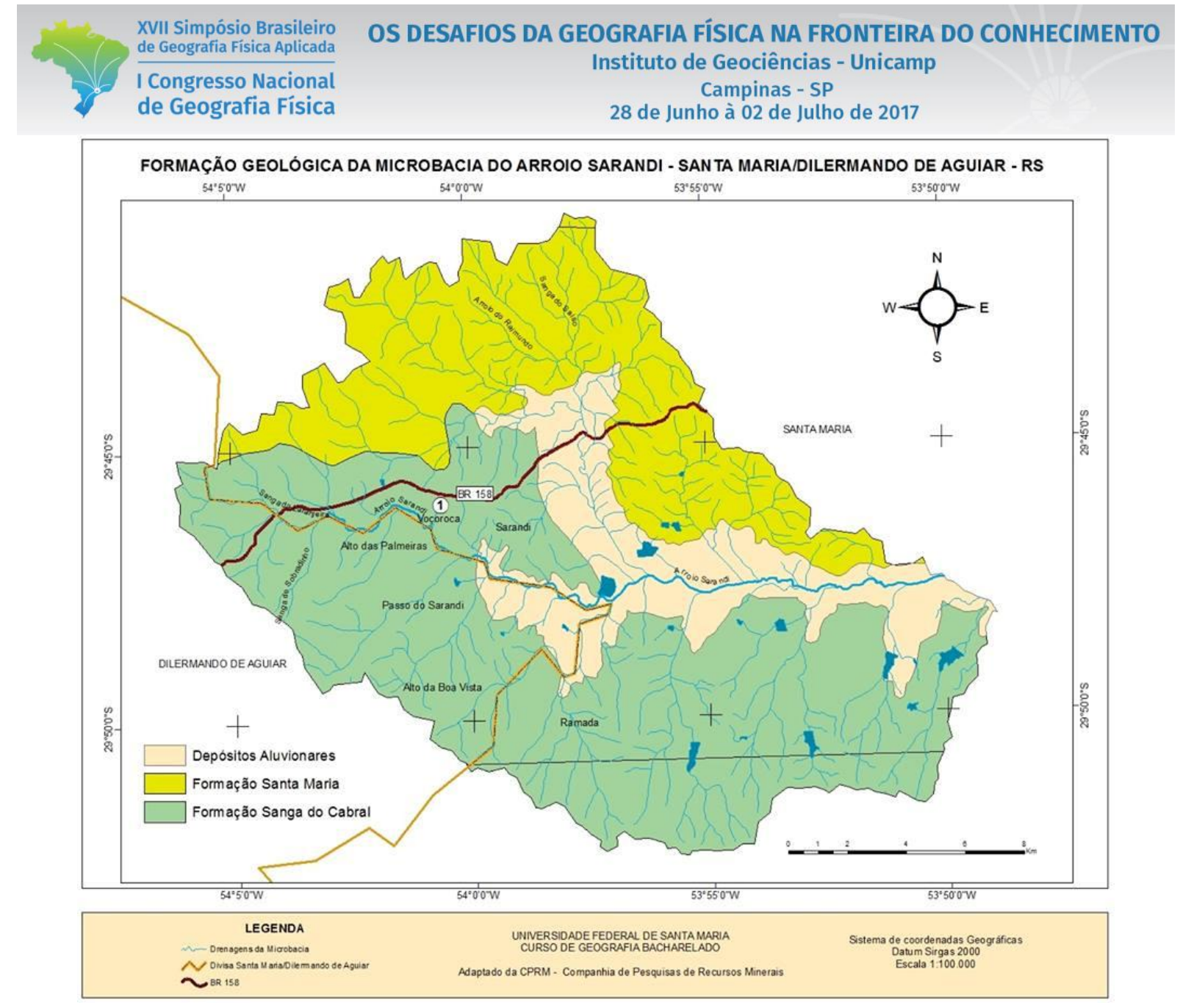

Figura 5 - Mapa geológico da microbacia do Arroio Sarandi. Fonte: Autor.

\section{Considerações finais}

O estudo realizado na bacia em questão oportuniza a criação de subsídios para o entendimento da dinâmica do processo erosivo em voçorocas. Em um próximo momento, as análises quanto à susceptibilidade de erosão das áreas serão iniciadas e complementadas com os aspectos morfométricos mais detalhados da rede hidrográfica. Realizar-se-ão, ainda, estudos referentes ao tipo de solo e à periodicidade das chuvas, bem como à contribuição desses fatores para o processo erosivo.

Durante a realização do trabalho ficou evidente a pertinência da análise ambiental por geoprocessamento, além da compatibilidade dos resultados prévios relacionados com a erosão. Esses fatores possibilitam o futuro monitoramento do avanço da voçoroca e a elaboração de um modelo digital de elevação preciso da área.

\section{Bibliografia}

ÁVILA, L. O. Erosão na microbacia do arroio Sarandi: Voçoroca do Buraco Fundo, Santa Maria/RS. 2009. 103 f. Dissertação (Mestrado em Geografia) - Universidade Federal de Santa Maria, Santa Maria, 2009. 
BASTOS, C. A. B. Estudo Geotécnico sobre a erodibilidade de solos residuais não saturados. 1999. 298 f. Tese (Doutorado em Engenharia) - Universidade Federal do Rio Grande do Sul, Porto Alegre, 1999. Disponível em: <https://www.lume.ufrgs.br/bitstream/handle/10183/2978/000242000.pdf?sequence=1>. Acesso em: 23 fev. 2017

BERTONI, J.; LOMBARDI NETO, F. Conservação do solo. São Paulo: Livroceres, 1985.

BOARDMAN, J. Soil erosion on the South Downs. A review. In: BOARDMAN, J.; FOSTER, I. D. L.; DEARING, J. A. (Eds.). Soil erosion on agricultural land. Chichester: Wiley, 1990. p. 87-105.

CÂMARA, G.; DAVIS, C.; MONTEIRO, A. M. Introdução à Ciência da Geoinformação. São José dos Campos: INPE, 2001. Disponível em: <http://www.dpi.inpe.br/gilberto/livro/introd/>. Acesso em: 23 fev. 2017.

CÂMARA, G; MEDEIROS, J. S.; MONTEIRO, A. M. Representações Computacionais do Espaço: Um Diálogo e a Ciência da Geoinformação. São José dos Campos: DPI/INPE, 2002.

COMPANHIA DE PESQUISA DE RECURSOS MINERAIS (CPRM). Serviço Geológico do Brasil. 2010. Disponível em: <http://www.cprm.gov.br>. Acesso em: 13 jan. 2017.

CUNHA, M. A. (Coord.). Manual de ocupação de encostas. São Paulo: IPT, 1991.

EMPRESA BRASILEIRA DE PESQUISA AGROPECUÁRIA (EMBRAPA). Brasil em relevo. Disponível em: <http://www.relevobr.cnpm.embrapa.br/download/rs/rs.htm>. Acesso em: 13 jan. 2017.

ESRI $囚$. ArcGIS Resources center. How Flow Direction works. 2011. Disponível em: <http://help.arcgis.com/en/arcgisdesktop/10.0/help/index.html\#//009z00000063000000.htm>. Acesso em: 3 jan. 2017.

GUERRA, A. T. Dicionário geológico-geomorfológico. 4. ed. Rio de Janeiro: IBGE, 1975.

SILVA, A. M.; SCHULZ, H. E.; CAMARGO, P. B. Erosão e hidrossedimentologia em bacias hidrográficas. São Carlos: Rima, 2003.

SOBRINHO et al. Delimitação automática de bacias hidrográficas utilizando dados SRTM. Revista Engenharia Agrícola, Jaboticabal, v. 30, p. 46-57, 2010.

SOUSA, A. T. de. Caracterização de voçorocas em bordas de relevo residual tabular em Quirinópolis. 2010. 170 f. Tese (Doutorado em) - Universidade Federal de Goiás, Goiânia, 2010.

VITTE, A. C.; GUERRA, A. J. T. (Orgs.). Reflexões sobre a geografia física do Brasil. São Paulo: Bertrand Brasil, 2004. p. 225-256. 